\title{
Functional analysis of Arabidopsis WRKY25 transcription factor in plant defense against Pseudomonas syringae
}

\author{
Zuyu Zheng1, Stephen L Mosher², Baofang Fan1, Daniel F Klessig² and \\ Zhixiang Chen*1
}

Address: ${ }^{1}$ Department of Botany and Plant Pathology, Purdue University, West Lafayette, IN 47907-2054, USA and ${ }^{2}$ Boyce Thompson Institute for Plant Research, Tower Road, Cornell University, Ithaca, NY 14853, USA

Email: Zuyu Zheng - zhengz@purdue.edu; Stephen L Mosher - slm72@cornell.edu; Baofang Fan - bfan@purdue.edu; Daniel F Klessig - dfk8@cornell.edu; Zhixiang Chen* - zhixiang@purdue.edu

* Corresponding author

Published: 10 January 2007

BMC Plant Biology 2007, 7:2 doi:10.1 186/147|-2229-7-2
Received: 15 September 2006

Accepted: 10 January 2007

This article is available from: http://www.biomedcentral.com/I47I-2229/7/2

(c) 2007 Zheng et al; licensee BioMed Central Ltd.

This is an Open Access article distributed under the terms of the Creative Commons Attribution License (http://creativecommons.org/licenses/by/2.0), which permits unrestricted use, distribution, and reproduction in any medium, provided the original work is properly cited.

\begin{abstract}
Background: A common feature of plant defense responses is the transcriptional regulation of a large number of genes upon pathogen infection or treatment with pathogen elicitors. A large body of evidence suggests that plant WRKY transcription factors are involved in plant defense including transcriptional regulation of plant host genes in response to pathogen infection. However, there is only limited information about the roles of specific WRKY DNA-binding transcription factors in plant defense.
\end{abstract}

Results: We analyzed the role of the WRKY25 transcription factor from Arabidopsis in plant defense against the bacterial pathogen Pseudomonas syringae. WRKY25 protein recognizes the TTGACC W-box sequences and its translational fusion with green fluorescent protein is localized to the nucleus. WRKY25 expression is responsive to general environmental stress. Analysis of stress-induced WRKY25 in the defense signaling mutants nprl, sid2, ein2 and coil further indicated that this gene is positively regulated by the salicylic acid (SA) signaling pathway and negatively regulated by the jasmonic acid signaling pathway. Two independent T-DNA insertion mutants for WRKY25 supported normal growth of a virulent strain of $P$. syringae but developed reduced disease symptoms after infection. By contrast, Arabidopsis constitutively overexpressing WRKY25 supported enhanced growth of $P$. syringae and displayed increased disease symptom severity as compared to wild-type plants. These WRKY25-overexpressing plants also displayed reduced expression of the SA-regulated $P R I$ gene after the pathogen infection, despite normal levels of free SA.

Conclusion: The nuclear localization and sequence-specific DNA-binding activity support that WRKY25 functions as a transcription factor. Based on analysis of both T-DNA insertion mutants and transgenic overexpression lines, stress-induced WRKY25 functions as a negative regulator of SA-mediated defense responses to $P$. syringae. This proposed role is consistent with the recent finding that WRKY25 is a substrate of Arabidopsis MAP kinase 4, a repressor of SA-dependent defense responses. 


\section{Background}

Plants are subjected to constant attack by a variety of microbial pathogens and herbivores and they have evolved a complex battery of defense mechanisms that are activated by multiple defense signaling pathways. Thus, in response to infection by some microbial pathogens, the interacting EDS1 and PAD4 proteins are induced and activated; these proteins positively regulate biosynthesis of salicylic acid (SA) and SA-dependent defense signaling pathways [1]. Other defense pathways mediated by ethylene (ET) and jasmonic acid (JA) also can be activated by certain pathogens and herbivores [2,3]. Genetic and molecular analyses indicate that these distinct defense pathways cross-talk extensively and their relationship can be synergistic or antagonistic [4].

Activation of plant defense responses following pathogen infection is associated with induction of a large number of host genes [5]. Some of the pathogen-induced genes encode proteins with direct anti-microbial activities (e.g. the hydrolytic glucanases and chitinases that degrade cell walls of microbial organisms) or enzymes involved in biosynthesis of anti-microbial compounds (e.g. phytoalexins), whereas others encode proteins with regulatory functions in the defense signaling pathways. Many of these defense genes appear to be induced at the transcriptional level through the specific recognition of cis-acting promoter elements and trans-acting sequence-specific DNA-binding transcription factors. Several classes of transcription factors have been implicated in plant defense responses, including DNA-binding proteins containing the novel WRKY zinc-finger motif [6]. Although originally thought to be plant specific, genes encoding WRKY proteins have been found in two non-photosynthetic eukaryotes, the slime mold Dictyostelium and the protist Giardia lamblia. The latter two organisms evolutionally precede the divergence of plants from animals and fungi, indicating an ancient origin of WRKY transcription factors [6,7]. However, WRKY genes have greatly proliferated and form large superfamilies in angiosperms, with more than 70 members in Arabidopsis [6,7].

A growing body of evidence suggests that WRKY proteins play important roles in regulating genes associated with plant defense responses. For example, pathogen infection or treatment with elicitors or SA rapidly induces WRKY gene expression in several plant species [8-17]. In Arabidopsis, expression of many WRKY genes was differentially regulated after pathogen infection or SA treatment [13]. Moreover, many defense-related genes, including several Pathogenesis-Related (PR) genes and the regulatory NPR1 gene, contain W-box elements in their promoters $[8,15,18-22]$. W-box sequences are specifically recognized by WRKY proteins and are necessary for inducible expression of these genes $[8,15,18-22]$.
In addition to this indirect evidence, several studies have revealed direct links between specific WRKY proteins and plant defense responses. Virus-induced silencing of three WRKY genes in tobacco compromised $N$ gene-mediated resistance to Tobacco mosaic virus [23]. Additionally, the Arabidopsis resistance gene RRS1, which confers resistance to the bacterial pathogen Ralstonia solanacearum, encodes a novel WRKY protein, WRKY52, that combines typical TIR-NBS-LRR R protein motifs with a WRKY domain [24,25]. Moreover, two Arabidopsis WRKY genes (WRKY22 and WRKY29) were shown to be induced by a MAP kinase pathway that mediates resistance responses to both bacterial and fungal pathogens and expression of WRKY29 in transiently transformed leaves led to reduced disease symptoms [26]. Likewise, constitutive expression of Arabidopsis WRKY18 and WRKY70 conferred constitutive or enhanced expression of defense-related genes, including SA-induced PR1, and increased resistance to virulent pathogens $[27,28]$. Interestingly while overexpression of Arabidopsis WRKY18 activated SA-regulated PR1 gene expression and enhanced resistance to $P$. syringae, its coexpression with genes encoding its interacting partner WRKY40 or WRKY60 had opposite effects on Arabidopsis resistance to the bacterial pathogen [29].

In a previously reported study using yeast two-hybrid screening, Arabidopsis MAP kinase 4 (MPK4), an activator of JA/ET-mediated defense and a repressor of SA-dependent resistance [30], was found to interact with a MPK4 substrate MKS1 that, in turn, interacts with Arabidopsis WRKY25 and WRKY33 [31]. In addition, WRKY25 and WRKY33 were phosphorylated by MPK4 in vitro and a wrky33 knockout mutant expressed elevated levels of PR1 under a short-day growth condition [31]. These results suggest that WRKY25 and WRKY33 may function as downstream components of the MPK4-mediated SArepressing and JA/ET-activating signaling pathways. Indeed, we have recently shown that disruption of WRKY33 results in enhanced susceptibility to necrotrophic fungal pathogens and impaired expression of JA/ ET-regulated defense genes [32]. No such phenotypes were observed in the wrky25 T-DNA insertion mutants. These results indicate that WRKY33 functions as a positive regulator of JA/ET-mediated pathways and plays an important role in disease resistance to necrotrophic fungal pathogen.

SA-mediated signaling has been shown to play a critical role in Arabidopsis responses to infection by Pseudomonas syringae $[33,34]$. We therefore used this model system to investigate the role of WRKY25 in the activation of defense responses. WRKY25 specifically bound the W-box sequence and was localized in the nucleus. In addition, WRKY25 is induced by a variety of environmental stress stimuli, including SA and ET treatment. Further linking 
WRKY25 with defense signaling, transgenic Arabidopsis constitutively overexpressing WRKY25 displayed reduced pathogen-induced PR1 gene expression and enhanced susceptibility to virulent $P$. syringae pv. maculicola strain ES4326 (PsmES4326). By contrast, two independent TDNA insertion mutants for WRKY25 developed milder disease symptoms than wild type plants after PsmES4326 infection. These results suggest that WRKY25 plays a negative role in SA-regulated $P R 1$ gene expression and resistance to $P$. syringae.

\section{Results}

\section{Structure, DNA binding and subcellular localization}

Arabidopsis WRKY25 (At2g30250) encodes a protein of 394 amino acids with a molecular weight of $44.134 \mathrm{kD}$ and an isolelectric point of 6.43 (Figure 1A). Based on the presence of two WRKY domains, WRKY25 is classified as a group I WRKY protein. The N-terminus and the region between the WRKY domains are rich in serine and/or threonine residues (Figure 1A). Thus, WRKY25 may be regulated, at least in part, via protein phosphorylation by a protein kinase(s) such as MPK4 [31].

WRKY transcription factors are thought to function by binding their cognate TTGACC/T W-box cis-elements in the promoter regions of target genes and activating or repressing their expression [6]. A number of isolated WRKY proteins have been shown to bind W-box sequences $[8,12,20]$. To examine the DNA-binding activity of WRKY25, we expressed the gene in E. coli, purified the recombinant protein, and assayed its binding to an oligonucleotide that contains two direct TTGACC repeats (Pchn5; Figure 1B) using EMSA. Several WRKY25/DNA complexes with differing mobility were detected when purified recombinant WRKY25 protein was incubated with the Pchn5 probe (Figure 1C). Whether the different complexes represent probes in which one or both of the $\mathrm{W}$ boxes are bound by WRKY25, or whether they are caused by formation of monomeric and oligomeric WRKY25 complexes is unclear. Alternatively, some of these complexes might result from protein degradation or incompletely translation of the WRKY25 gene. Binding of WRKY25 was not detected with a mutant probe (mPchn5) in which both TTGACC sequences were changed to TTGAAC (Figure 1B and 1C). Thus, binding of WRKY25 to the TTGACC W-box sequence is highly specific.

If WRKY25 is a transcription factor, it is likely to be localized in the nucleus. The presence of putative nuclear localization signal predicted by the PSORT II program is consistent with this possibility. To determine the subcellular location of WRKY25, we constructed a GFP protein fusion of WRKY25. The fusion construct, driven by the Cauliflower mosaic virus (CaMV)35S promoter, was directly bombarded into onion (Allium cepa) epidermal cells. As shown in Figure 2, the transiently expressed WRKY25-GFP fusion protein was localized exclusively to the nucleus. By contrast, GFP was found in both the nucleus and cytoplasm due to its small size (Figure 2).

\section{Expression of WRKY25}

A possible role for WRKY25 during defense signaling was further investigated by analyzing its expression in Arabidopsis after inoculation with PsmES4326. As shown in Figure 3A, WRKY25 mRNA levels increase in wild-type plants after infiltration with either the control $\mathrm{MgCl}_{2}$ solution (mock inoculation) or the bacterial suspension. However, WRKY25 expression was prolonged in pathogen-infected plants, as transcript levels remained elevated at 24 hours post infiltration (hpi), whereas they were nearly undetectable in $\mathrm{MgCl}_{2}$-treated plant at this time (Figure 3A).

To determine whether WRKY25 expression is influenced by the SA, ET and/or JA signaling pathways, WRKY25 expression was monitored in various signaling mutants. Induced WRKY25 expression was modestly reduced in the npr1-3 and sid2 mutants, which are defective in SA signaling and biosynthesis, respectively [35,36] (Figure 3A). By contrast, no significant difference was observed in WRKY25 expression between the wild-type plants and the ET-insensitive ein 2 mutant plants following mock or pathogen inoculation. Analysis of the JA-insensitive coi1 mutant revealed a delay in WRKY25 expression following mock inoculation; however, it was significantly enhanced after pathogen infiltration, as compared with that observed in wild-type plants (Figure 3A). These results suggest that WRKY25 expression is sensitive to environmental cues and it appears to be positively regulated by the SA signaling pathway but negatively regulated by the JA pathway.

We also analyzed WRK25 induction in wild-type plants sprayed with water, SA, 1-aminocyclopropane-1-carboxylic acid (ACC, the immediate precursor of ET) or methyl JA. WRKY25 expression was rapidly induced in watertreated plants (Figure $3 \mathrm{~B}$ ), underscoring that the gene is very responsive to environmental stimuli. Plants sprayed with SA or ACC accumulated greater levels of WRKY25 transcripts than water-sprayed plants, whereas JA-treated plants accumulated less (Figure 3B). Thus, both SA and ET regulate WRKY25 expression in a positive manner, whereas JA has a negative effect on WRKY25 expression.

\section{Disrupting or altering WRKY25 expression affects disease resistance and symptom severity}

To analyze the role of WRKY25 in disease resistance, we identified two T-DNA insertion mutants for WRKY25. wrky25-1 (Salk_136966) contains a T-DNA insertion in the promoter region while wrky25-2 (Sail 754_A03) contains a T-DNA insertion in the last intron of the WRKY25 


\section{A}

\begin{abstract}
MSSTSFTDLLGSS GVD CYEDDEDLRVS GSSFG GYYPERTGS G LPKFKTA QP P PLPISQSSHNFTF S Y LDSPLLLSSSHSLISPTT G TFPLQGFNGTTNNHSDFP W QL SQP SNASSALQETYGVQDHE KKQE MIPNEIAT QNNN QSF GTER QIKIPAYMVSRNSNDGYG WR KYGQKQVKKSENPRSYFKCTYP D CVSKKIVETASD G QITEIYK G G HN HPKPEFTKRPS QS SLPSSVNGRRLFNPASVVSEPHDQS ENSSISFDYSDLEQKSEKSEY GE IDEEEEQPEMKRMKREGEDE GMSIEVSK GVKEP RVVV QTISDIDVLID GFR WRKY G QKVVK GN TNPRSYYKCTEQG $\underline{C} G V K K Q V E R S A A D E R A V L T T Y E G R \underline{H N} \underline{H} D I$ PTALRRS
\end{abstract}

B

Pchn5: GGAACTTGACCATCCGTTGACCGGGCTGCAGGAATTCG mP chn5: GGAACTTGAACATCCGTTGAACGGGCTGCA G GATTCG

C

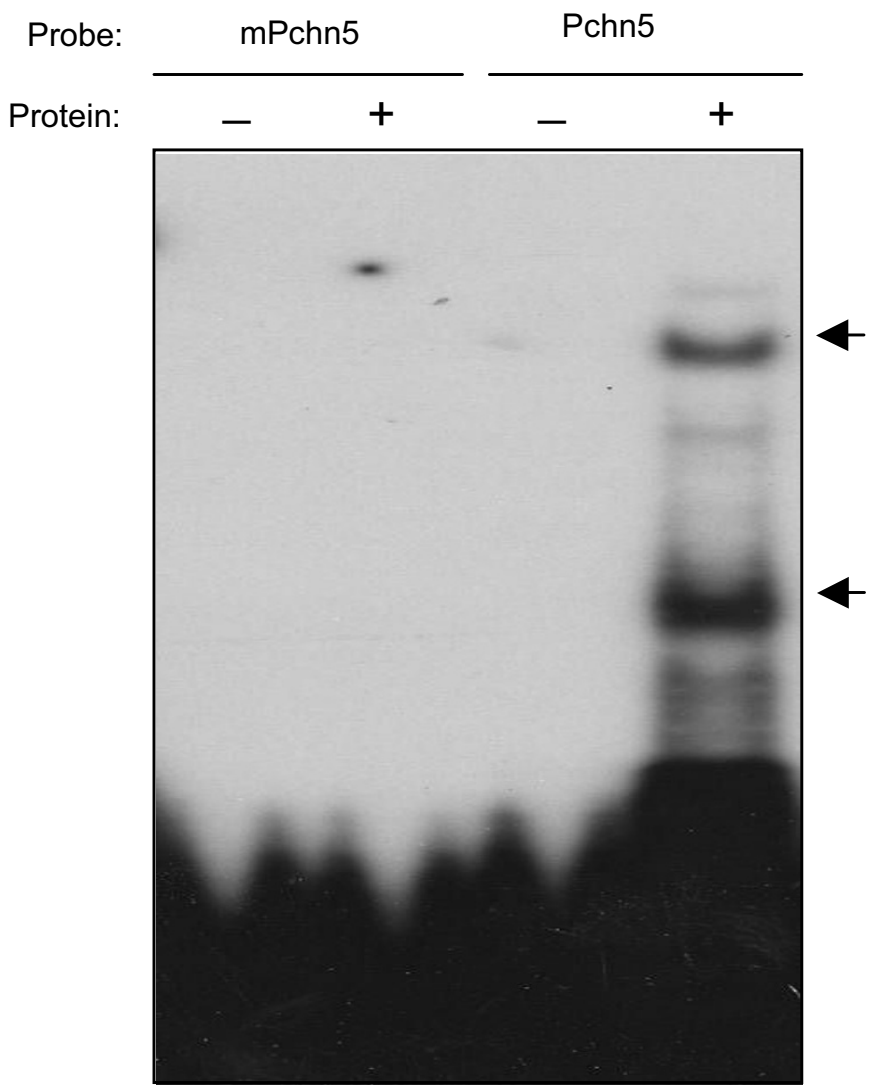

\section{Figure I}

Sequence and DNA-binding Activity of WRKY25. A. Amino acid sequence of WRKY25. The two WRKY motifs are indicated with the highly conserved WRKYGQK sequence and the residues forming the $\mathrm{C}_{2} \mathrm{H}_{2}$ zinc fingers underlined. $B$. Oligonucleotides used in the electrophoretic mobility shifting assay (EMSA). The Pchn5 probe contains two direct W-box repeats, while in the mPchn5 probe, the TTGACC sequences are mutated to TTGAAC. The wild-type and mutated W-box sequences are underlined. C. EMSA to test binding of recombinant WRKY25 to the W box motif in the Pchn5 probe. Binding reactions containing WRKY25 and Pchn5 produced two major DNA/protein complexes, which are indicated by arrows. Change of the TTGACC to TTGAAC in the mPchn5 probe abolished WRKY25 binding. No retarded bands were detected in the absence of the recombinant WRKY25 protein. 


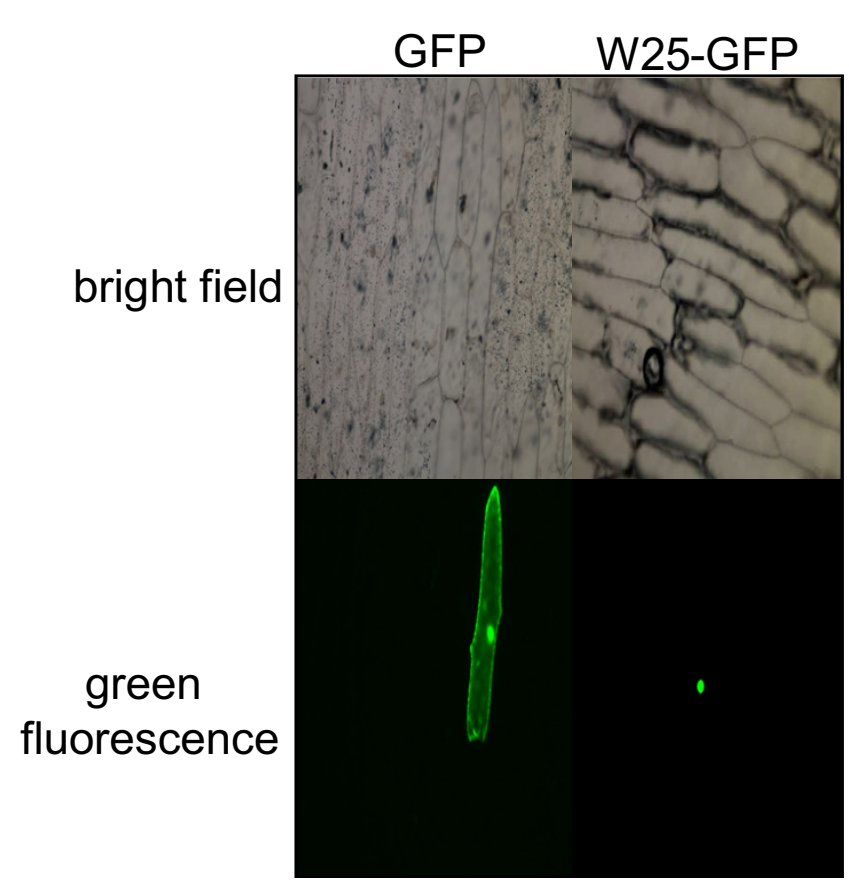

\section{Figure 2}

Localization of WRKY25 in vivo. WRKY25 was fused to GFP to yield W25-GFP; this chimeric protein was localized to the nucleus of onion epidermal cells. GFP alone was detected in both the nucleus and the cytoplasm due to its small size. Bright-field image of the onion epidermal cells are shown in the top panels.

gene (Figure 4A). Homozygous mutant plants were identified by PCR with WRKY25-specific primers. We then compared the wild-type and wrky25 mutants for Induced accumulation of WRKY25 transcripts. Since $\mathrm{MgCl}_{2}$ treatment and pathogen infection had almost the same potency in inducing WRKY25 expression (Figure 3), we used only pathogen infection in these experiments. Northern analysis using a full-length WRKY25 cDNA clone as the probe detected WRKY25 transcripts in wildtype plants but not in wrky25-1 plants after pathogen infection. By contrast, a WRKY25 transcript of reduced size was detected in pathogen-infected wrky25-2 plants (Figure 4B, upper panel). This transcript was not detected when the same blot was probed with a DNA fragment corresponding to the region downstream of the T-DNA insertion site in wrky25-2 (Figure 4B, lower panel). Thus, the TDNA insertion in the wrky25-2 mutant results in generation of a truncated WRKY25 transcript that is predicted to generate a truncated WRKY25 protein lacking the C-terminal WRKY domain, which is important for DNA binding [37].
Analysis of both wrky25 mutants revealed no difference in growth or morphology from that of wild-type plants; flowering also occurred at the normal time. Following inoculation with PsmES4326, the mutant lines supported similar levels of bacterial growth as wild-type plants (Figure 5A). However, the inoculated leaves of wrky25-1 and wrky 25-2 plants consistently displayed less disease symptom than wild-type plants (Figure 5B).

To examine the effect of WRKY25 overexpression, we generated plants containing a full-length WRKY25 cDNA driven by the CaMV $35 S$ promoter (35S::W25). Northern blotting identified several transgenic plants that contained elevated levels of WRKY25 transcript constitutively (Figure 4C). Two transgenic lines (\#12 and \#18 in Figure 4C) that constitutively expressed WRKY25 at elevated levels and contain a single T-DNA locus in their genomes, based on the ratio of antibiotic resistance phenotypes, were chosen for further study.

Analysis of $\mathrm{T}_{3}$ homozygous plants from both lines revealed no difference in growth or development from that of wild-type plants, although their leaf color appear to be slightly paler. Following inoculation with PsmES4326, the transgenic 35S:W25 overexpression lines displayed substantially greater bacterial growth ( 12 fold) than wild-type plants (Figure 5A). The inoculated leaves of WRKY25-overexpressing plants also developed more severe disease symptoms than those of wild-type plants after infection (Figure 5B).

\section{PRI gene expression and SA accumulation}

To study the molecular basis for the altered responses to PsmES4326 infection, PR1 gene expression was monitored. Consistent with the enhanced susceptibility phenotype, WRKY25 overexpressing lines contained substantially lower levels of PR1 transcripts than wildtype plants (Figure 6A). In contrast, PR1 transcript levels in the wrky 25 mutants were comparable to those in wildtype plants (Figure 6A).

To determine whether altered PR1 induction in the WRKY25-overexpressing plants correlated with reduced SA accumulation, the levels of both free SA and SA-glucoside conjugates (SAG) were monitored. Both wild-type plants and the T-DNA insertion mutants displayed similar levels of free SA and SAG following PsmES4326 infection (Figure 6B). Free SA levels in WRKY25-overexpressing plants were comparable to those in wild-type plants at 0 and $24 \mathrm{hpi}$; however, the level of free SA at 48 hpi was somewhat lower than in wild-type plants. SAG levels in uninoculated WRKY25-overexpressing plants also were 10-fold lower than those in wild-type plants, although they rose to nearly wild-type levels after infection (Figure 6B). 
A

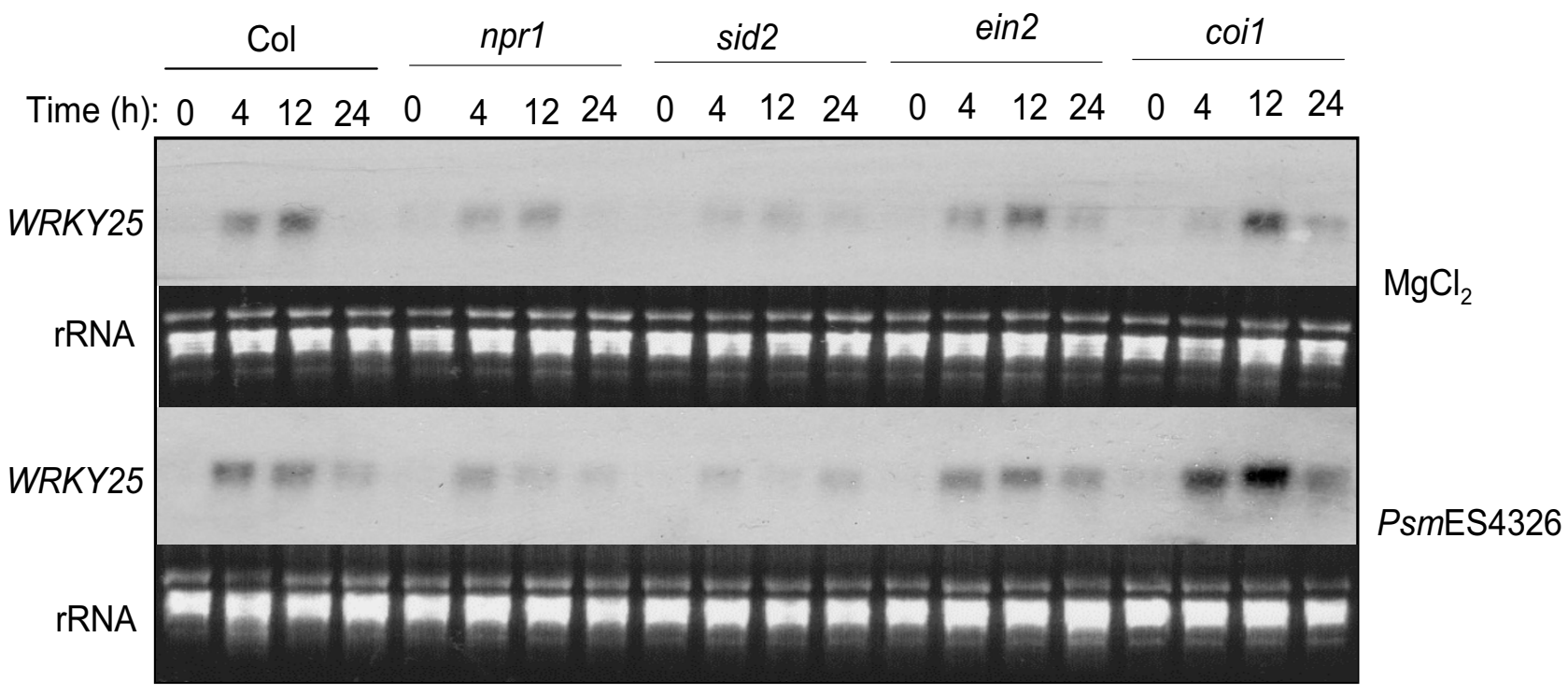

B

\begin{tabular}{|c|c|c|c|c|c|c|c|c|c|c|c|c|c|c|c|c|c|}
\hline \multirow[b]{2}{*}{ Time (h) } & \multirow[b]{2}{*}{0} & \multicolumn{4}{|c|}{$\mathrm{H}_{2} \mathrm{O}$} & \multicolumn{4}{|c|}{ SA } & \multicolumn{4}{|c|}{ MeJA } & \multicolumn{4}{|c|}{ ACC } \\
\hline & & 1 & 4 & 8 & 24 & 0 & 1 & 4 & 24 & 1 & 4 & 8 & 24 & 1 & 4 & 8 & 24 \\
\hline WRKY25 & 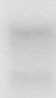 & 6 & $=$ & 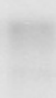 & & D. & \% & $=$ & 87 & $=$ & & $=$ & & & $=$ & $=$ & $1=$ \\
\hline JA & E & $\Rightarrow$ & 틀 & ㅍ & $\bar{E}$ & $E$ & $E$ & $=$ & $\Rightarrow$ & 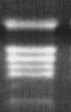 & E & $\equiv$ & $\bar{E}$ & $\equiv$ & & $\bar{E}$ & $\bar{E}$ \\
\hline
\end{tabular}

Figure 3

Expression of WRKY25. A. RNA blot analysis of WRKY25 expression in 5-week old wild-type or mutant Arabidopsis. Two fully expanded leaves were infiltrated with $10 \mathrm{mM} \mathrm{MgCl}_{2}$ (mock inoculation) or Psm ES4326 $\left(\mathrm{OD}_{600}=0.000 \mathrm{I}\right.$ in $\left.10 \mathrm{mM} \mathrm{MgCl}\right)$ and harvested at the indicated times after inoculation. After separation on a gel and blotting to nylon membrane, the blot was probed with a WRKY25-specific DNA fragment. B. Induced WRKY25 expression in 5-week old wild-type Arabidopsis plants sprayed with $\mathrm{H}_{2} \mathrm{O}, 2 \mathrm{mMSA}, 0.1 \mathrm{mM}$ ACC or $0.1 \mathrm{mM}$ methyl JA. Leaves were harvested at the indicated times after treatment and used for preparation of total RNA and RNA blotting. Ethidium bromide stained rRNA was used as a loading control. The experiments were repeated twice with similar results.

\section{Discussion and Conclusion}

To determine whether WRKY25 is a transcription factor that regulates disease resistance, we analyzed its role in Arabidopsis responses to the bacterial pathogen $P$. syringae. Consistent with this putative function, WRKY25 is a nuclear-localized, DNA-binding protein that specifically recognizes the TTGAC W-box sequences (Figures 1 and 2). Analysis of WRKY25 expression revealed that it is highly responsive to a variety of biotic and abiotic stress conditions (Figure 3). In wild-type plants, pathogen infection induced prolonged WRKY25 expression, whereas induction by mock inoculation was more transient. SA treatment also induced WRKY25 expression over that observed in water-treated plants, whereas it was reduced in JAtreated plants. Further arguing that the SA and JA signaling pathways play positively and negatively roles in regulating 


\section{A}

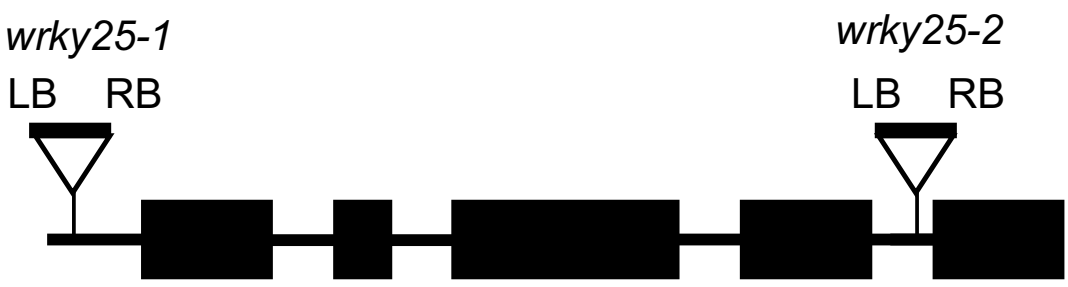

B
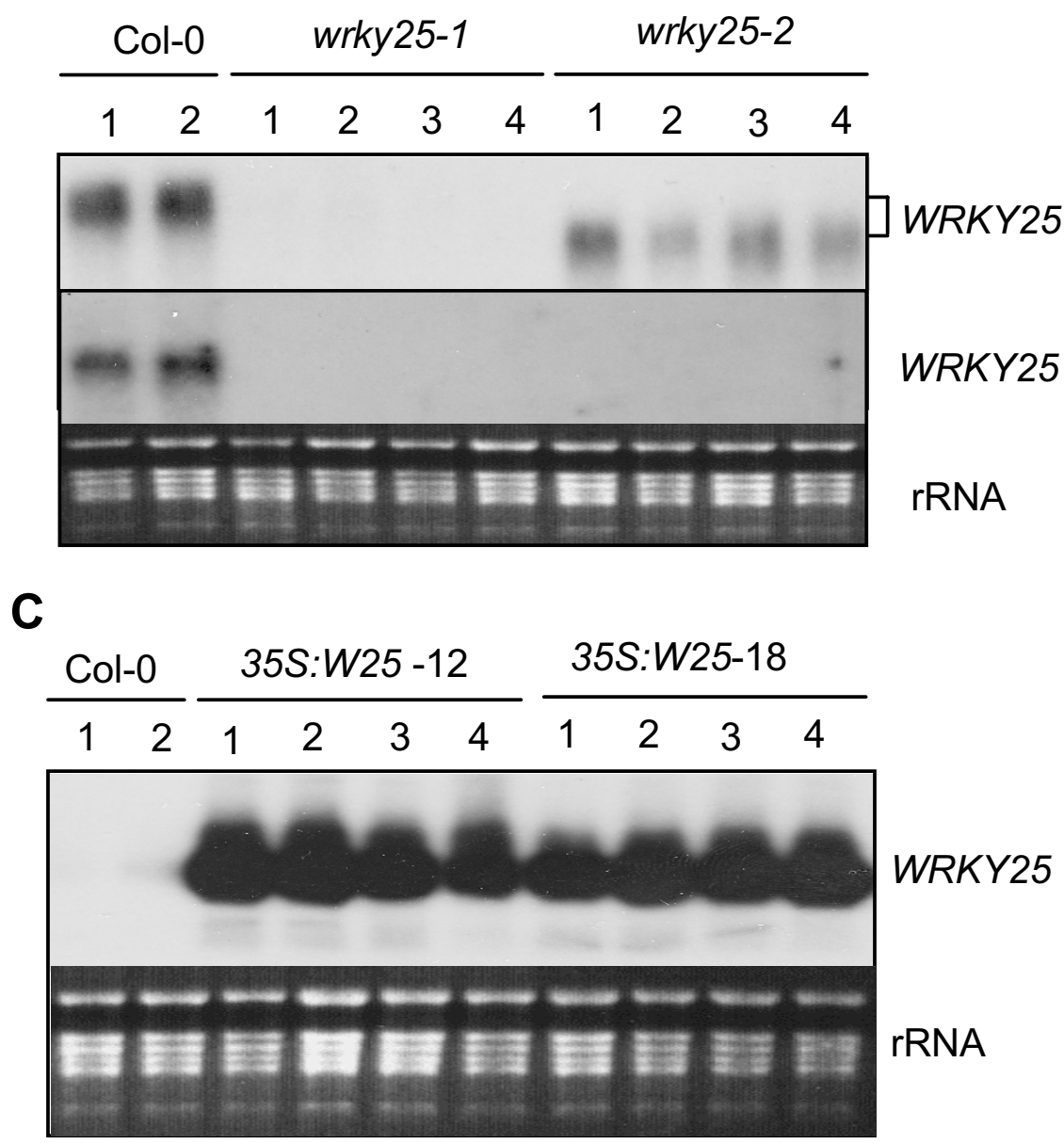

\section{Figure 4}

Characterization of wrky25 T-DNA insertion mutants and transgenic overexpressing plants. A. Diagram of WRKY25 gene and its T-DNA insertion mutants. B. RNA blot analysis of wrky25 mutant lines. Four hours after inoculation with PsmES4326 $\left(O D_{600}=0.000 \mathrm{I}\right)$, the inoculated leaves from two wild-type plants $(\mathrm{Col}-0)$ or four wrky25-I and wrky25-2 mutant plants were harvested and total RNA was isolated. After separation and blotting to a nylon membrane, the blot was probed with a fulllength WRKY25 cDNA fragment (upper panel) or a WRKY25 DNA fragment corresponding to the region downstream of the T-DNA insertion in the wrky25-2 mutant (lower panel). Ethidium bromide stained rRNA was used as a loading control. C. RNA blot analysis of WRKY25 expression in transgenic plants constitutively overexpressing WRKY25. RNA samples were prepared from leaves of two wild-type plants (Col-0) or four plants from each tansgenic 35S:WRKY25 line and probed with a WRKY25-specific DNA probe. Lines 12 and 18 expressed elevated levels of WRKY25 and contain a single T-DNA insertion based on the ratio of antibiotic-resistant progeny. F3 homozygous progeny plants of the two lines were used for further analyses. 
A

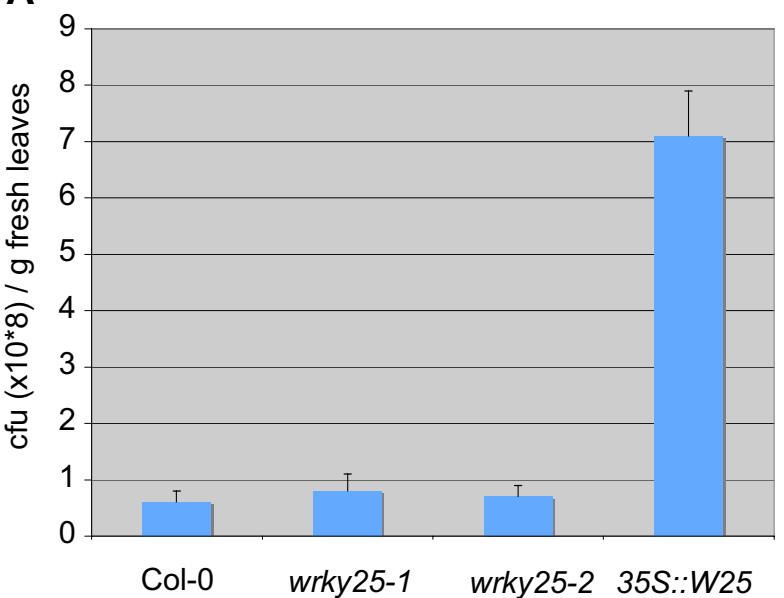

B

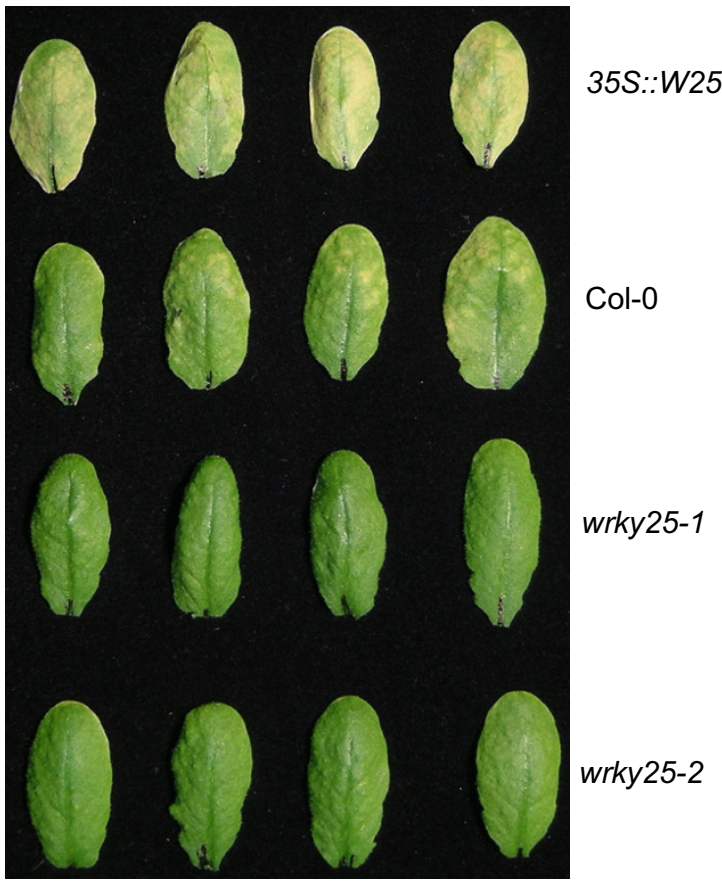

Figure 5

Responses of the wrky25 mutant and transgenic 35S:WRKY25 plants to $P$. syringae. A. Bacterial titer in wild type (Col-0), wrky 25 insertion mutant and $\mathrm{F} 3$ progeny of transgenic 35S:WRKY25 plants (line I2) at 3 days post inoculation (dpi) with PsmES4326 $\left(\mathrm{OD}_{600}=0.000 \mathrm{I}\right)$. The means and standard errors were calculated from six replicates. Analysis of F3 progeny from $35 \mathrm{~S}:$ WRKY25 line 18 yielded similar results to those observed for 35S:WRKY25 line 12. B. Disease symptom development in wild type (Col-0), wrky25 mutants and transgenic 35S:WRKY25 plants inoculated with PsmES4326 (OD 600 $=0.000 \mathrm{I}$ ). Pictures of representative inoculated leaves were taken at 4 dpi. These experiments were repeated two additional times with similar results.
WRKY25 induction, respectively, was the demonstration that pathogen-induced WRKY25 expression was reduced in npr1-3 and sid2 mutants and enhanced in the coil mutant. Although JA frequently works with ET to signal defense responses, the role of ET in WRKY25 expression is unclear. ACC treatment induced WRKY25 expression, but pathogen-induced expression of this gene was unaffected in the ein 2 mutant. Taken together, these results indicate that multiple signaling pathways associated with stress responses influence WRKY25 induction.

Strong evidence that this stress-induced WRKY gene functions as a negative regulator of defense against $P$. syringae comes from analysis of both transgenic overexpression lines and two T-DNA insertion mutants. Constitutive overexpression of WRKY25 suppressed pathogen-induced PR1 expression and enhanced both bacterial growth and symptom development as compared with wild-type plants, whereas the wrky25 mutants displayed reduced disease symptoms. Since the wrky25-1 and wrky25-2 mutants supported wild-type levels of bacterial growth, PR1 expression and SA accumulation, it is possible that WRKY25 exerts its negative effect(s) primarily by promoting disease symptom development. Consistent with this possibility, several studies have suggested that bacterial growth and symptom development are not necessarily linked and can be differentially affected by host genes. For example, the ET-insensitive ein2 mutant supports normal bacterial growth but develops reduced chlorosis after infection by $P$. syringae as compared to wild-type plants [38]. In addition, disruption of the Arabidopsis BOTRYTISSUSCEPTIBLE 1 (BOS1) gene, which encodes a R2R3 MYB transcription factor, causes enhanced disease symptoms after infection of $P$. syringae without affecting bacterial growth [39].

Alternatively, the observation that WRKY25-overexpressing plants displayed increased bacterial growth and enhanced disease symptoms suggests that this protein promotes both processes. If so, one possible explanation for why bacterial growth was unaffected in the wrky 25 mutants is that WRKY25 function might vary depending on its expression level and/or biological context. Thus, relatively low-level and possibly tissue-specific expression of WRKY25, as in the wild-type plants, might promote symptom development, whereas the high-level, non-specific expression, as in the overexpression lines, might promote both disease symptoms and bacterial growth. Alternatively, functional redundancy between various members of the large WRKY gene family might mask the effect of a mutation in a single WRKY gene. WRKY25 shares very similar protein structure with WRKY33 and they also display similar pathogen-induced expression patterns $[13,40]$. To test possible functional redundancy between the two WRKY proteins, we have generated double knock- 
A

\begin{tabular}{|c|c|c|c|c|c|c|c|c|c|c|c|c|}
\hline \multirow[b]{2}{*}{ Day: } & \multicolumn{3}{|c|}{ Col-0 } & \multicolumn{3}{|c|}{ 35S:W25 } & \multicolumn{3}{|c|}{ wrky25-1 } & \multicolumn{3}{|c|}{ wrky25-2 } \\
\hline & 0 & 1 & 2 & 0 & 1 & 2 & 0 & 1 & 2 & 0 & 1 & 2 \\
\hline PR1 & & & & & & & & & & & & \\
\hline & & & & & & & & & & & & \\
\hline
\end{tabular}

B

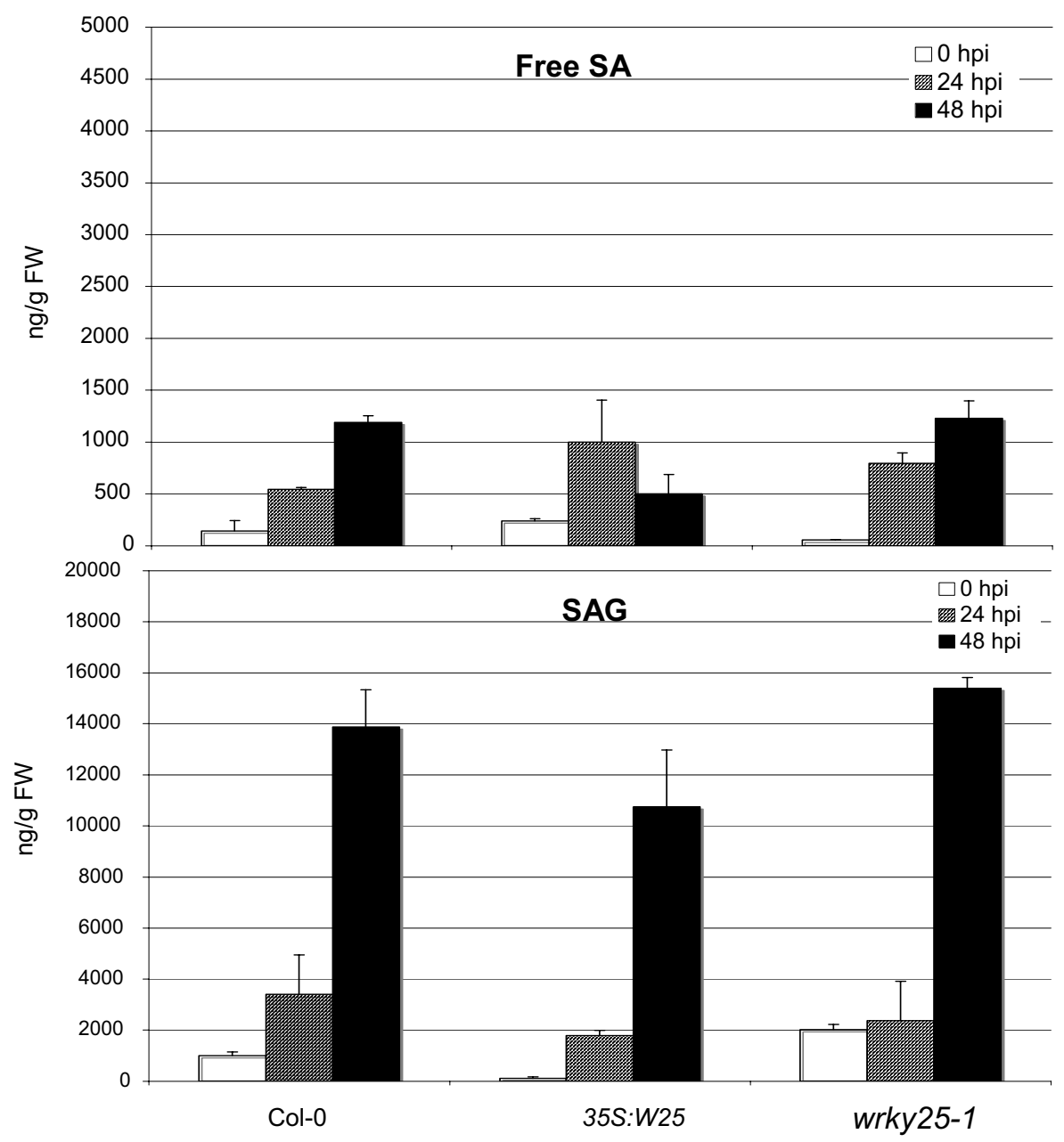

Figure 6

Pathogen-induced PRI expression and SA accumulation. A. RNA blot analysis of PRI expression in wild type (Col-0), F3 progeny of transgenic 35S:WRKY25 plants (line I2) and wrky25 mutants following inoculation with PsmES4326 (OD $600=0.000 \mathrm{I})$. Total RNA was isolated from inoculated leaves harvested at indicated times after inoculation and probed with a PRI probe. Ethidium bromide-stained rRNA was used as a loading control. The experiment was repeated two additional times with similar results. B. Determination of free and SA glucoside (SAG) levels in wild type (Col-0), transgenic 35S:WRKY25 plants (line I2) and the wrky25 mutants after inoculation with PsmES4326 $\left(\mathrm{OD}_{600}=0.000 \mathrm{I}\right)$. Inoculated leaves were harvested at indicated times for SA and SA glucoside (SAG) determination. The means and standard errors were calculated from 2-3 replicate samples. FW, fresh weight. 
out mutants for the two genes but observed no further enhancement in the phenotypes of disease resistance to either necrotrophic fungal pathogens or $P$. syringae (Zheng and Chen, unpublished results).

A growing body of evidence indicates that pathogen infection can activate multiple signaling pathways in the regulation of diverse defense mechanisms [4,41]. SA-mediated signaling pathway(s), for example, play important roles in defense against biotrophic pathogens and in activation of systemic acquired resistance against a diverse range of microbial pathogens [41]. Defense pathways mediated by JA and/or ET, on the other hand, are more effective against herbivores and necrotrophic pathogens [41]. While these distinct defense pathways can sometimes function cooperatively, they often are antagonistic. SA has been shown to play an important role in signaling resistance to $P$. syringae $[34,35,42]$. Thus, one possible mechanism through which WRKY25 negatively regulates defense responses after $P$. syringae infection is by repressing the SA signaling pathway. Supporting this possibility, plants overexpressing WRKY25 displayed reduced pathogen-induced expression of $P R 1$, a molecular marker for SA-mediated defense pathways. Since these overexpressing plants accumulated nearly wild-type levels of free SA, WRKY25 may work at a point downstream of SA to repress defense responses. Previous studies have revealed that suppression of the SA signaling pathway enhances the activation of JA-induced responses. Thus, we tested whether WRKY25 overexpressing lines and/or wrky25 mutants displayed altered responses to two necrotrophic fungal pathogens, Botrytis cinerea and Alternaria brassicicola. Neither the WRKY25 overexpression lines nor the mutants lines displayed altered fungal growth or symptom development (unpublished results).

It was recently demonstrated that WRKY25 is phosphorylated by MPK4 in vitro; WRKY25 also interacts with MKS1, a substrate of MPK4 [31]. These results, together with our analysis, suggest that WRKY25 functions in the MPK4 signaling pathway that represses SA-mediated defense responses. WRKY33 appears to function largely as an activator of JA/ET-mediated signaling [32]. These studies support that these two WRKY transcription factors function in the MPK4-mediated SA-repressing and JA/ETactivating signaling pathways. In addition, our analyses revealed that WRKY25 expression is induced by abiotic stress, such as infiltration with $\mathrm{MgCl}_{2}$ or spraying with water. Previous studies have demonstrated that WRKY25 also is induced by oxidative stress, heat shock and wounding [43]. Thus, this transcription factor may play a role in responses to abiotic as well as biotic stresses. However, transgenic plants constitutively expressing WRKY25 were not more tolerant to oxidative stress, as measured by root growth on agar plates in the presence or absence of the superoxide-generating agent paraquat [43]. Whether our WRKY25 overexpression plants and/or the loss-of-function mutants exhibit altered responses to other abiotic stress conditions has not been determined. Future studies in this direction may reveal not only additional roles for WRKY25 in plant defense and stress responses, but also possible interactions between their respective signaling pathways.

\section{Methods \\ Materials}

$\left[\alpha-{ }^{32} \mathrm{P}\right] \mathrm{dATP}(>3,000 \mathrm{Ci} / \mathrm{mmol})$ was obtained from New England Nuclear; other common chemicals were purchased from Sigma. Arabidopsis plants were grown in growth rooms at $22^{\circ} \mathrm{C}$ and $120 \mu \mathrm{Em}^{-2} \mathrm{~s}^{-1}$ light on a 12 hour light and 12 hour dark photoperiod. SA was dissolved in water as a $100 \mathrm{mM}$ stock solution and adjusted to $\mathrm{pH} 6.5$ with $\mathrm{KOH}$. SA was applied by spraying the plants with a $2 \mathrm{mM}$ solution. MeJA was dissolved in $50 \%$ ethanol as a $10 \mathrm{mM}$ stock solution and diluted to $100 \mu \mathrm{M}$ with water before spraying onto plants. ACC was dissolved in water as a $10 \mathrm{mM}$ stock solution and was diluted to $100 \mu \mathrm{M}$ before spraying the plants.

\section{Northern blotting}

Total RNA was isolated from leaves using the TRIZOL reagent (BRL Life Technologies, Rockville, MD). For RNA gel blot analysis, total RNA $(4 \mu \mathrm{g})$ was separated on $1.2 \%$ agarose-formaldehyde gels and blotted to nylon membranes. Blots were hybridized with [ $\alpha-32$ P]dATP labeled gene-specific probes. Hybridization was performed in PerfectHyb plus hybridization buffer (Sigma) overnight at $68^{\circ} \mathrm{C}$. The membrane was then washed for 10 minutes twice with $2 \times$ SSC ( $1 \times$ SSC is $0.15 \mathrm{M} \mathrm{NaCl}$ and $0.015 \mathrm{M}$ sodium citrate) and $1 \%$ SDS and for 10 minutes with $0.1 \times$ SSC and $1 \%$ SDS at $68^{\circ} \mathrm{C}$. Transcripts for WRKY25 were detected with a full-length WRKY25 cDNA as probe unless otherwise indicated. Transcripts for PR1 were detected using a PR1 fragment generated from PCR amplification using two PR1-specific oligonucleotides as primers (5'-TTCTTCCCTCGAAAGCTCAA-3' and 5'-CGTTCACATAATTCCCACGA-3').

\section{Production of recombinant WRKY25 protein and electrophoresis mobility shift assay (EMSA)}

To generate the WRKY25 recombinant protein, its fulllength cDNA was amplified using two gene-specific primers (5'-ATCGAATTCATGGACAATAGCAGAAC-3' and 5'ATCCTCGAGTGAGGGCATAAACGAAT-3'). The amplified DNA fragment was digested with EcoR1 and Xho1, cloned into the same sites of pET32a (Novagen) and transformed into Escherichia coli strain BL21(DE3). Induction of expression and purification of recombinant Histagged WRKY25 protein were performed according to the protocol provided by Novagen. The purified proteins were 
dialyzed overnight against a nuclear extract buffer $(25 \mathrm{mM}$ HEPES/KOH at pH 7.5, $40 \mathrm{mM} \mathrm{KCl}, 0.1 \mathrm{mM}$ EDTA, 10\% glycerol, $1 \mathrm{mM}$ DTT and $30 \mathrm{mg} \mathrm{ml} / \mathrm{l} \mathrm{PMSF}$ ) at $4{ }^{\circ} \mathrm{C}$. The double-stranded synthetic oligonucleotide Pchn5 was designed based on the sequence from the promoter of the tobacco basic chitinase gene [18] with two $\mathrm{W}$ boxes separated by 5 nucleotides. Pchn 5 and the mutant mPchn 5 probes were labeled to specific activities of approximately $10^{5} \mathrm{cpm} / \mathrm{ng}$ using the Klenow fragment of DNA polymerase I. Sequence-specific DNA binding was assayed with EMSA essentially as described previously [12]. Binding reactions contained $12 \mu \mathrm{l}$ nuclear extraction buffer, $5 \mu \mathrm{g}$ poly(dIdC), $1 \mu \mathrm{g}$ proteins and $2 \mathrm{ng}$ of labeled doublestranded oligo DNA. DNA and protein complexes were allowed to form at room temperature for $30 \mathrm{~min}$ and resolved on a $10 \%$ polyacrylamide gel in $0.5 \times \mathrm{TBE}$ at $4{ }^{\circ} \mathrm{C}$.

\section{Subcellular localization}

Full length WRKY25 coding sequence was amplified with two gene-specific primers (5'-ATCGAATTCATGGACAATAGCAGAAC-3' and 5'-ATCCCATGGTGGGCATAAACGAATCG-3'). The amplified fragment was digested with EcoR1 and Nco 1 and cloned into a GFP vector behind the CaMV $35 S$ promoter. The empty GFP plasmid was used as a control. Transient expression of the GFP fusion proteins in onion epidermal cells through particle bombardment of the GFP construct plasmid DNA was performed essentially as described [44].

\section{Construction of transgenic lines}

To generate the 35S:WRKY25 construct, the cDNA fragment that contained the full coding sequence and $3^{\prime}$ untranslated region of WRKY 25 was excised from a cloning plasmid and subcloned into the same restriction sites of the Agrobacterium transformation vector pOCA30 [27] in the sense orientation behind the CaMV $35 S$ promoter. Arabidopsis transformation was performed by the floral dip procedure [45]. The seeds were collected from the infiltrated plants and selected in MS medium containing $50 \mu \mathrm{g} / \mathrm{ml}$ kanamycin. Kanamycin-resistant plants were transferred to soil nine days later and grown in a growth chamber.

\section{Identification of the wrky25 T-DNA insertion mutants}

The T-DNA insertion flanking sequences of the Syngenta Arabidopsis insertion library and Salk T-DNA insertion population [46] were searched with the genomic sequence of WRKY25. Confirmation of the T-DNA insertions was done by PCR analysis using a combination of a gene specific primer (5'-CGGTTTCACACTTGACGATTT-3' for wrky25-1 and 5'-GCAAAAGGTTTCTTCTTGGGT-3' for wrky 25-2) and a T-DNA border primer (5'-GCTTGCTGCAACTCTCTCAG-3' for wrky25-1 and 5'-TAGCATCTGAATTTCATAACCAATCTCGATACAC-3' for wrky25-2). The nature and locations of the T-DNA insertions were confirmed by sequencing the PCR products. Another PCR was performed to identify plants homozygous for the TDNA insertions using the above gene-specific primers and respective reverse primers (5'-AGACCCGGTTCTCTCTGGAT-3' for wrky25-1 and 5'-TCACGAGCGACGTAGCGCGGT-3' for wrky25-2).

\section{Pathogen infection}

Pathogen inoculation was performed by infiltrating the leaves of at least six plants for each treatment with either $10 \mathrm{mM} \mathrm{MgCl}_{2}$ (mock inoculation) or a suspension of the bacterial pathogen $P$. syringae. PsmES4326 was cultured until $\mathrm{OD}_{600}=0.6-1$ in liquid King's medium B with an appropriate antibiotic at $28^{\circ} \mathrm{C}$. After collecting the cells by centrifugation, the cells were re-suspended in $10 \mathrm{mM}$ $\mathrm{MgCl}_{2}$ and adjusted to appropriate concentrations for plant infiltration. To assess bacterial growth, leaves were weighed, homogenized in $10 \mathrm{mM} \mathrm{MgCl}$ and appropriate dilutions were plated onto King's medium $B$ agar supplemented with appropriate antibiotics. After incubation for 48 hours at $28^{\circ} \mathrm{C}$, the number of colony-forming units (cfu) per gram of infected leaf tissue was determined.

\section{Determination of SA}

Free SA and SAG were extracted and quantified as described previously [47].

\section{Authors' contributions}

$\mathrm{ZZ}$ carried out the molecular characterization of the WRKY25 protein and functional analysis of the mutants and drafted the manuscript. SLM carried out quantification of SA. BF carried out isolation of the mutants and participated in their characterization. DFK participated in the design of the study and edited the manuscript. ZC conceived of the study, participated in the design and helped to draft and edit the manuscript. All authors read and approved the final manuscript.

\section{Acknowledgements}

We would like to thank RIKEN Bioresource Center for the full-length cDNA clone for WRKY25, and Syngenta Biotechnology, Inc and Salk Institute for the wrky25 T-DNA insertion mutants. We would also like to thank the Arabidopsis Resource Center at the Ohio State University and Fred Ausubel (Massachusetts General Hospital, Boston, MA) for the Arabidopsis mutants and Jane Glazebrook (University of Minnesota, St. Paul, MN) for the $P$. syringae strain. We are grateful to Dr. D'Maris Dempsey for her critical reading of the manuscript. This work was supported in part by the US National Science Foundation grants MCB-0209819 to ZC and MCB0 II 0404 to DFK. This is journal paper 2006-I8057 of the Purdue University Agricultural Research Program.

\section{References}

I. Feys BJ, Moisan LJ, Newman MA, Parker JE: Direct interaction between the Arabidopsis disease resistance signaling proteins, EDSI and PAD4. Embo J 200I, 20(19):5400-54II.

2. Turner JG, Ellis C, Devoto A: The jasmonate signal pathway. Plant Cell 2002, I 4 Suppl:SI53-64. 
3. Wang KL, Li H, Ecker JR: Ethylene biosynthesis and signaling networks. Plant Cell 2002, I 4 Suppl:SI3I-5I.

4. Glazebrook J, Chen W, Estes B, Chang HS, Nawrath C, Metraux JP, Zhu T, Katagiri F: Topology of the network integrating salicylate and jasmonate signal transduction derived from global expression phenotyping. Plant J 2003, 34(2):2 I7-228.

5. Rushton PJ, Somssich IE: Transcriptional control of plant genes responsive to pathogens. Curr Opinion Plant Biol 1998, I:3। I-3 I5.

6. Ulker B, Somssich IE: WRKY transcription factors: from DNA binding towards biological function. Curr Opin Plant Biol 2004, 7(5):49|-498.

7. Zhang Y, Wang L: The WRKY transcription factor superfamily: its origin in eukaryotes and expansion in plants. $B M C$ Evol Biol 2005, 5(I): I.

8. Rushton PJ, Torres JT, Parniske M, Wernert P, Hahlbrock K Somssich IE: Interaction of elicitor-induced DNA-binding proteins with elicitor response elements in the promoters of parsley PR I genes. Embo J I996, I5(20):5690-5700.

9. Eulgem T, Rushton PJ, Schmelzer E, Hahlbrock K, Somssich IE: Early nuclear events in plant defence signalling: rapid gene activation by WRKY transcription factors [In Process Citation] Embo J 1999, I 8(17):4689-4699.

10. Hara K, Yagi M, Kusano T, Sano H: Rapid systemic accumulation of transcripts encoding a tobacco WRKY transcription factor upon wounding. Mol Gen Genet 2000, 263(I):30-37.

II. Dellagi A, Helibronn J, Avrova AO, Montesano M, Palva ET, Stewart HE, Toth IK, Cooke DE, Lyon GD, Birch PR: A potato gene encoding a WRKY-like transcription factor is induced in interactions with Erwinia carotovora subsp. atroseptica and Phytophthora infestans and is coregulated with class I endochitinase expression [In Process Citation]. Mol Plant Microbe Interact 2000, 13(10): 1092-1101.

12. Chen $C$, Chen Z: Isolation and characterization of two pathogen- and salicylic acid- induced genes encoding WRKY DNAbinding proteins from tobacco. Plant Mol Biol 2000, 42(2):387-396.

13. Dong J, Chen C, Chen Z: Expression profile of the Arabidopsis WRKY gene superfamily during plant defense response. Plant Mol Biol 2003, 5 I:2I-37.

14. Eckey C, Korell M, Leib K, Biedenkopf D, Jansen C, Langen G, Kogel $\mathrm{KH}$ : Identification of powdery mildew-induced barley genes by CDNA-AFLP: functional assessment of an early expressed MAP kinase. Plant Mol Biol 2004, 55(I): I-I5.

15. Turck F, Zhou A, Somssich IE: Stimulus-dependent, promoterspecific binding of transcription factor WRKYI to Its native promoter and the defense-related gene PcPRI-I in Parsley. Plant Cell 2004, I6(10):2573-2585.

16. Kim CY, Zhang S: Activation of a mitogen-activated protein kinase cascade induces WRKY family of transcription factors and defense genes in tobacco. Plant $J$ 2004, 38(I): I42-I5I.

17. Kalde M, Barth M, Somssich IE, Lippok B: Members of the Arabidopsis WRKY group III transcription factors are part of different plant defense signaling pathways. Mol Plant Microbe Interact 2003, 16(4):295-305.

18. Yang P, Wang Z, Fan B, Chen C, Chen Z: A pathogen- and salicylic acid-induced WRKY DNA-binding activity recognizes the elicitor response element of the tobacco class I chitinase gene promoter. Plant J 1999, I8:14|-|49.

19. Willmott RL, Rushton PJ, Hooley R, Lazarus CM: DNase I footprints suggest the involvement of at least three types of transcription factors in the regulation of alpha-Amy2/A by gibberellin. Plant Mol Biol 1998, 38(5):8I7-825.

20. Yu D, Chen $C$, Chen Z: Evidence for an important role of WRKY DNA binding proteins in the regulation of NPRI gene expression. Plant Cell 200 I, I3(7): I527-1540.

21. Rocher A, Dumas C, Cock JM: A W-box is required for full expression of the SA-responsive gene SFR2. Gene 2005, 344: $181-192$.

22. Yamamoto S, Nakano T, Suzuki K, Shinshi H: Elicitor-induced activation of transcription via $W$ box-related cis-acting elements from a basic chitinase gene by WRKY transcription factors in tobacco. Biochim Biophys Acta 2004, 1679(3):279-287.

23. Liu Y, Schiff M, Dinesh-Kumar SP: Involvement of MEK I MAPKK NTF6 MAPK, WRKY/MYB transcription factors, COII and CTRI in $\mathrm{N}$-mediated resistance to tobacco mosaic virus. Plant J 2004, 38(5):800-809.
24. Deslandes L, Olivier J, Peeters N, Feng DX, Khounlotham M, Boucher C, Somssich I, Genin S, Marco Y: Physical interaction between RRS I-R, a protein conferring resistance to bacterial wilt, and PopP2, a type III effector targeted to the plant nucleus. Proc Natl Acad Sci U S A 2003, I00(13):8024-8029.

25. Lahaye T: The Arabidopsis RRSI-R disease resistance gene-uncovering the plant's nucleus as the new battlefield of plant defense? Trends Plant Sci 2002, 7(1 0):425-427.

26. Asai T, Tena G, Plotnikova J, Willmann MR, Chiu WL, Gomez-Gomez L, Boller T, Ausubel FM, Sheen J: MAP kinase signalling cascade in Arabidopsis innate immunity. Nature 2002, 41 5(6875):977-983.

27. Chen $C$, Chen $Z$ : Potentiation of developmentally regulated plant defense response by AtWRKY 18, a pathogen-induced Arabidopsis transcription factor. Plant Physiol 2002, 129(2):706-716.

28. Li J, Brader G, Palva ET: The WRKY70 transcription factor: a node of convergence for jasmonate-mediated and salicylatemediated signals in plant defense. Plant Cell 2004, 16(2):3|9-33|

29. Xu X, Chen C, Fan B, Chen Z: Physical and Functional Interactions between Pathogen-Induced Arabidopsis WRKY I8, WRKY40, and WRKY60 Transcription Factors. Plant Cell 2006, 18(5): $1310-1326$

30. Petersen $M$, Brodersen $P$, Naested $H$, Andreasson $E$, Lindhart $U$, Johansen B, Nielsen HB, Lacy M, Austin MJ, Parker JE, Sharma SB, Klessig DF, Martienssen R, Mattsson O, Jensen AB, Mundy J: Arabidopsis map kinase 4 negatively regulates systemic acquired resistance. Cell 2000, 103(7): IIII-II20.

3I. Andreasson E, Jenkins T, Brodersen $P$, Thorgrimsen $S$, Petersen $N H$, Zhu S, Qiu JL, Micheelsen P, Rocher A, Petersen M, Newman MA, Bjorn Nielsen H, Hirt H, Somssich I, Mattsson O, Mundy J: The MAP kinase substrate MKSI is a regulator of plant defense responses. Embo / 2005, 24(I 4):2579-2589.

32. Zheng Z, Qamar SA, Chen Z, Mengiste T: Arabidopsis WRKY33 Transcription Factor Is Required for Resistance to Necrotrophic Fungal Pathogens. Plant J 2006, in press:

33. Dong $X: S A, J A$, ethylene, and disease resistance in plants. Curr Opin Plant Biol 1998, I(4):316-323.

34. Durrant WE, Dong $X$ : Systemic acquired resistance. Annu Rev Phytopathol 2004, 42: 185-209.

35. Cao H, Glazebrook J, Clarke JD, Volko S, Dong X: The Arabidopsis NPRI gene that controls systemic acquired resistance encodes a novel protein containing ankyrin repeats. Cell 1997, 88(I):57-63.

36. Nawrath C, Heck S, Parinthawong N, Metraux JP: EDS5, an essential component of salicylic acid-dependent signaling for disease resistance in Arabidopsis, is a member of the MATE transporter family. Plant Cell 2002, I 4(I):275-286.

37. Maeo K, Hayashi S, Kojima-Suzuki H, Morikami A, Nakamura K: Role of conserved residues of the WRKY domain in the DNAbinding of tobacco WRKY family proteins. Biosci Biotechnol Biochem 200I, 65(II):2428-2436.

38. Bent AF, Innes RW, Ecker JR, Staskawicz BJ: Disease development in ethylene-insensitive Arabidopsis thaliana infected with virulent and avirulent Pseudomonas and Xanthomonas pathogens. Mol Plant Microbe Interact 1992, 5(5):372-378.

39. Mengiste T, Chen $X$, Salmeron J, Dietrich R: The BOTRYTIS SUSCEPTIBLEI gene encodes an R2R3MYB transcription factor protein that is required for biotic and abiotic stress responses in Arabidopsis. Plant Cell 2003, I 5(I I):255I-2565.

40. Eulgem T, Rushton PJ, Robatzek S, Somssich IE: The WRKY superfamily of plant transcription factors. Trends Plant Sci 2000, 5(5): 199-206

4I. Glazebrook J: Contrasting Mechanisms of Defense Against Biotrophic and Necrotrophic Pathogens. Annu Rev Phytopathol 2004

42. Jirage $D$, Tootle TL, Reuber TL, Frost LN, Feys BJ, Parker JE, Ausubel FM, Glazebrook J: Arabidopsis thaliana PAD4 encodes a lipaselike gene that is important for salicylic acid signaling. Proc Nat Acad Sci U S A 1999, 96(23): I 3583-13588.

43. Rizhsky L, Davletova S, Liang H, Mittler R: The zinc finger protein ZatI2 is required for cytosolic ascorbate peroxidase I expression during oxidative stress in Arabidopsis. J Biol Chem 2004, 279(I 2): I |736-II743. 
44. Kinkema M, Fan W, Dong $X$ : Nuclear localization of NPRI is required for activation of PR gene expression. Plant Cell 2000, I 2(I 2):2339-2350.

45. Clough SJ, Bent AF: Floral dip: a simplified method for Agrobacterium-mediated transformation of Arabidopsis thaliana. Plant J 1998, 16(6):735-743.

46. Alonso JM, Stepanova AN, Leisse TJ, Kim CJ, Chen H, Shinn P, Stevenson DK, Zimmerman J, Barajas P, Cheuk R, Gadrinab C, Heller C, Jeske A, Koesema E, Meyers CC, Parker H, Prednis L, Ansari Y, Choy N, Deen H, Geralt M, Hazari N, Hom E, Karnes M, Mulholland C Ndubaku R, Schmidt I, Guzman P, Aguilar-Henonin L, Schmid M, Weigel D, Carter DE, Marchand T, Risseeuw E, Brogden D, Zeko A Crosby WL, Berry CC, Ecker JR: Genome-wide insertional mutagenesis of Arabidopsis thaliana. Science 2003, 30I(5633):653-657.

47. Bowling SA, Guo A, Cao H, Gordon AS, Klessig DF, Dong X: A mutation in Arabidopsis that leads to constitutive expression of systemic acquired resistance. Plant Cell 1994, 6(12): 1845-1857.

Publish with Bio Med Central and every scientist can read your work free of charge

"BioMed Central will be the most significant development for disseminating the results of biomedical research in our lifetime. "

Sir Paul Nurse, Cancer Research UK

Your research papers will be:

- available free of charge to the entire biomedical community

- peer reviewed and published immediately upon acceptance

- cited in PubMed and archived on PubMed Central

- yours - you keep the copyright

Submit your manuscript here:

http://www.biomedcentral.com/info/publishing_adv.asp
BiolMedcentral 